\title{
Learning curve for endoscopic thyroidectomy: a single teaching hospital study
}

This article was published in the following Dove Press journal:

OncoTargets and Therapy

22 January 2013

Number of times this article has been viewed

\section{Feilin Cao \\ Ketao Jin \\ Binbin Cui \\ Bojian Xie}

Department of Surgical Oncology, Taizhou Hospital, Wenzhou Medical College, Linhai, Zhejiang, People's Republic of China
Correspondence: Ketao Jin Department of Surgical Oncology, Taizhou Hospital,Wenzhou Medical College, I50 Ximen Road, Linhai, Zhejiang 317000, People's Republic of China

$\mathrm{Tel}+865768519905$ I

Fax +8657685199876

Email jinketao200।@yahoo.com.cn
Background: Endoscopic thyroidectomy allows surgeons to remove a thyroid tumor from a remote site, while providing excellent results from a cosmetic viewpoint. Endoscopic thyroidectomy via the breast approach is a recent technique that requires a learning curve. Research on the learning curve for endoscopic thyroidectomy could be a method for investigating the surgical outcome.

Methods: This retrospective study investigated 100 consecutive patients who underwent endoscopic thyroidectomy performed by a single endoscopist over a period of 5 years. From January 2007 to December 2011, 100 of 355 patients scheduled for endoscopic thyroidectomy selected the breast approach. We divided the patients into four groups. Each group consisted of 25 patients: group A (cases 1-25), group B (cases 26-50), group C (cases 51-75), and group D (cases 76-100).

Results: The operative times for groups A, B, C, and D were 100.52 $\pm 25.13,80.34 \pm 20.22$, $72.42 \pm 15.33$, and $63.35 \pm 15.11$ minutes, respectively $(P<0.05)$.

Conclusion: After 25 cases, we observed that endoscopic thyroidectomy via the breast approach enables a shorter mean operative time and a reduced complication rate.

Keywords: endoscopic thyroidectomy, thyroidectomy, learning curve, thyroid complications

\section{Introduction}

Thyroid is one of the largest endocrine glands, and is found in the neck, inferior to the thyroid cartilage. Thyroid disorders include hyperthyroidism, hypothyroidism, and thyroid nodules. Nodules are commonly benign neoplasms, but may be cancerous. All these disorders can lead to goiter, a swelling of the thyroid gland that can cause a swelling in the neck. Some thyroid disorders need surgical treatment, including a thyroid nodule with a diameter more than $1 \mathrm{~cm}$ and fine needle aspiration biopsy for a suspected neoplasm, ${ }^{1,2}$ a thyroid nodule with a diameter less than $1 \mathrm{~cm}$ and fine needle aspiration indeterminate more than once, ${ }^{1,2}$ a thyroid nodule and fine needle aspiration positive for malignancy, ${ }^{2-4}$ multiple thyroid nodules having the same malignant possibility as one positive nodule, ${ }^{5,6}$ differentiated thyroid cancer, ${ }^{7}$ medullary thyroid cancer, ${ }^{8,9}$ prophylaxis in cases with multiple endocrine neoplasia syndrome, ${ }^{10}$ anaplastic carcinoma, ${ }^{11}$ and thyrotoxic disease. ${ }^{12}$

Endoscopic thyroidectomy and robotic thyroidectomy (the da Vinci surgical system) allow surgeons to remove a thyroid tumor from a remote site, while providing excellent results from a cosmetic viewpoint. ${ }^{13-15}$ The goals of endoscopic thyroidectomy are to limit external scarring and improve cosmesis, to reduce postoperative pain, to enhance postoperative recovery, and to achieve these ends without compromising 
treatment efficacy. Endoscopic thyroidectomy was first described by Hüscher et al in $1997 .{ }^{16}$ Most of the earlier endoscopic approaches to the thyroid gland employed small cervical incisions in the midline or laterally. To avoid a visible scar on the neck, noncervical approaches to the thyroid gland have been used. The most commonly used noncervical approaches are axillary, ${ }^{17}$ via the breast, ${ }^{18}$ lateral, ${ }^{19}$ transoral, ${ }^{20}$ and also certain hybrid approaches, ${ }^{21}$ such as the bilateral axillary-breast approach, the bilateral axillo-breast approach, the unilateral axillo-breast approach, and the postauricular and axillary approach. Among these, the breast approach has emerged as a clear favorite, as evidenced by its exponential growth in the mainland of China. ${ }^{13,22,23}$

Although evidence-based data reporting short-term and long-term outcome data after endoscopic resection for different thyroid diseases have shown clear advantages in comparison with traditional procedures, endoscopic thyroidectomy has not been widely accepted. One of the reasons for this initial refusal is the technical difficulty of endoscopic resection requiring adequate training both in open and endoscopic procedures before gland resection can be performed safely. Study of the learning curve for endoscopic thyroidectomy could be a method for investigating the surgical outcome. The present study sought to evaluate the learning curve for duration of endoscopic thyroidectomy performed by a surgeon with wide experience in open thyroidectomy.

\section{Materials and methods}

\section{Patients}

From January 2007 to December 2011, 100 of 355 patients selected endoscopic thyroidectomy via the breast approach. All were concerned about the cosmetic appearance of the neck and chose this procedure as their preferred surgical treatment. The characteristics of the patients are shown in Table 1. This was a retrospective analysis of the surgical outcomes for the groups performed by the same group of surgeons. All operations were performed by a single surgeon (FC) assisted by two of the other authors (BX and BC). All cases were identified from a thyroid surgery patient database, prospectively maintained by one of the authors (BX). Informed consent was obtained from each patient before surgery in all cases. The study was approved by the institutional review board of our hospital.

All patients were evaluated preoperatively using ultrasonography, computed tomographic scan, and fine needle aspiration cytology. All patients underwent direct laryngoscopy preoperatively to assess vocal cord motility. The inclusion criteria used for endoscopic thyroidectomy are shown in Table 2. The main surgical outcome measures were operative time (interval from skin incision to skin closure), postoperative hospital stay, identification of recurrent laryngeal nerve, identification of parathyroid glands, conversion to an open surgical pro cedure, postoperative calcemia, postoperative vocal alteration, postoperative

Table I Clinical patient data

\begin{tabular}{|c|c|c|c|c|c|}
\hline & $\begin{array}{l}\text { Endoscopic } \\
\text { thyroidectomy } \\
(n=100)\end{array}$ & $\begin{array}{l}\text { Group A } \\
(n=25)\end{array}$ & $\begin{array}{l}\text { Group B } \\
(n=25)\end{array}$ & $\begin{array}{l}\text { Group C } \\
(n=25)\end{array}$ & $\begin{array}{l}\text { Group D } \\
(n=25)\end{array}$ \\
\hline \multicolumn{6}{|l|}{ Age (years) } \\
\hline Mean \pm SD & $35.52 \pm 11.69$ & $36.53 \pm 10.58$ & $36.62 \pm 11.73$ & $33.48 \pm 10.38$ & $35.42 \pm 11.56$ \\
\hline Range & $17-55$ & $19-48$ & $22-55$ & $17-43$ & $21-53$ \\
\hline \multicolumn{6}{|l|}{ Gender } \\
\hline Male (n/\%) & $5 / 5$ & $2 / 8$ & $1 / 5$ & $1 / 5$ & $1 / 5$ \\
\hline Female $(n / \%)$ & $95 / 95$ & $23 / 92$ & $24 / 95$ & $24 / 95$ & $24 / 95$ \\
\hline Body mass index (mean $\pm S D$ ) & $29 \pm 6.1$ & $28 \pm 5.3$ & $25 \pm 5.7$ & $3 I \pm 7.1$ & $30 \pm 6.4$ \\
\hline $\begin{array}{l}\text { Tumor size in diameter } \\
(\mathrm{mm} \text {, mean } \pm \mathrm{SD})\end{array}$ & $4.3 \pm 0.7$ & $4.0 \pm 0.9$ & $4.2 \pm 0.7$ & $4.5 \pm 0.5$ & $4.3 \pm 0.7$ \\
\hline \multicolumn{6}{|l|}{ Tumor localization } \\
\hline Right & 56 & 15 & 13 & 11 & 17 \\
\hline Left & 44 & 10 & 12 & 14 & 8 \\
\hline \multicolumn{6}{|l|}{ Operative methods } \\
\hline Unilateral lobectomy & 100 & 25 & 25 & 25 & 25 \\
\hline $\begin{array}{l}\text { Postoperative hospital stay } \\
\text { (days, mean } \pm \text { SD) }\end{array}$ & $5.5 \pm 0.50$ & $5.5 \pm 0.49$ & $5.4 \pm 0.51$ & $5.6 \pm 0.52$ & $5.5 \pm 0.48$ \\
\hline Conversion to open procedure & 0 & 0 & 0 & 0 & 0 \\
\hline RLN identification & 100 & 25 & 25 & 25 & 25 \\
\hline PG identification & 100 & 25 & 25 & 25 & 25 \\
\hline
\end{tabular}

Abbreviations: RLN, recurrent laryngeal nerves; PG, parathyroid gland; SD, standard deviation. 
Table 2 Inclusion criteria

No suspicion of malignancy

Fine needle aspiration cytology report of a benign thyroid lesion

Thyroid goiter or nodules $<5 \mathrm{~cm}$ in diameter

Thyroid gland volume $<25 \mathrm{~mL}$

No history of thyroiditis

No history of hyperthyroidism

No previous neck surgery

No irradiation

complications, and pathological characteristics. The following complications were analyzed: transient or permanent recurrent laryngeal nerve palsy, transient or permanent hypocalcemia, redo surgery for hemorrhage, and postoperative pain. Patients were tested for hypocalcemia preoperatively and on postoperative days 1 and 30 . All patients with a postoperative calcium level below the lower limit of the normal range $(8.2-10.6 \mathrm{mg} / \mathrm{dL})$ were considered to have hypocalcemia. In this study, hypocalcemia and recurrent laryngeal nerve palsy were defined as permanent when there was no evidence of recovery within 30 days after surgery. Patients in both groups were followed up at days 7 and 30 by office visit or phone call for hoarseness of voice, difficulty in swallowing, hypesthesia, and paresthesia. The data were analyzed for statistical significance using the Student's $t$-test and Chi-square test. $P$ values $<0.05$ were considered to be statistically significant.

\section{Surgical procedure}

The surgical procedure for endoscopic thyroidectomy via the breast approach has been described elsewhere. ${ }^{13}$ Briefly, endoscopic thyroidectomy was performed via the breast approach under general anesthesia and endotracheal intubation. Patients were placed in the supine position with extension of the neck. A $15 \mathrm{~mm}$ incision in the presternal region (for placement of the Hanson trocar) and two $5 \mathrm{~mm}$ incisions in the superior areas of both mammary areolas were performed. A dilute epinephrine saline solution $(1: 200,000)$ was injected into the subcutaneous space in the breast and subplatysmal space in the neck to ease flap dissection and to prevent bleeding. Using a standard curve access vascular tunneler (WL Gore and Associates Inc, Flagstaff, AZ), the working space was extended. After blunt dissection of the subcutaneous tissue of the anterior chest wall through this incision, a $15 \mathrm{~mm}$ trocar was inserted. The working area was maintained with low pressure $\mathrm{CO}_{2}$ insufflation at a pressure of $10 \mathrm{mmHg}$, and a 30-degree $5 \mathrm{~mm}$ flexible endoscope (Olympus, Tokyo, Japan) was inserted through the trocar. The working space was made wide to the level of the thyroid cartilage cranially and to the medial edge of each of the sternocleidomastoid muscles laterally with visual guidance by the endoscope. After the working space was set up, two $5 \mathrm{~mm}$ incisions were made and two $5 \mathrm{~mm}$ trocars were inserted. Thyroid vessel management and thyroidectomy were performed endoscopically using a $5 \mathrm{~mm}$ ultrasonic coagulation device (Harmonic scalpel, Ethicon Endosurgery, Somerville, NJ). After dissecting the strap muscles in the midline endoscopically, the isthmus was divided. Traction over the ipsilateral strap muscles was then oriented laterally to reveal the right lobe. After cutting the inferior thyroid arteries and veins and the middle thyroid vein, the lobe was retracted downwards to expose the superior thyroid arteries, which were then dissected using the Harmonic scalpel. Next, the lobe was gently lifted up and the whole cervical course of the recurrent laryngeal nerve up to the inferior constrictor muscle of the pharynx was traced and protected, as well as both the inferior and superior parathyroid glands. Magnification of the endoscope allowed easy identification of the recurrent laryngeal nerve and parathyroid glands.

Lastly, the lobe was excised from the inferior pole up towards the superior pole. The left lobe could be excised in the same manner as for the right lobe. The resected specimen was inserted into a retrieval bag and retrieved through the $15 \mathrm{~mm}$ port. A frozen section of the resected specimen was examined intraoperatively for pathological confirmation. Homeostasis was checked at the end of dissection. After cleaning the cavity with physiological saline solution, the strap muscles were sutured. An aspiration drainage tube was left in situ in the central compartment, and was removed 48 hours after surgery.

\section{Results}

All of the 100 cases met the inclusion criteria for endoscopic thyroidectomy. The mean age of the patients was $35.52 \pm 11.69$ (range 17-55) years. The male to female gender ratio was 5:95. All patients were treated by unilateral lobectomy. Patient characteristics are presented in Table 1.

The mean duration of surgery for each group was $100.52 \pm 25.13,80.34 \pm 20.22,72.42 \pm 15.33$, and $63.35 \pm 15.11$ minutes, respectively. Comparison of neighboring groups showed differences in operative time between groups $\mathrm{A}$ and $\mathrm{B}(P<0.05)$, groups $\mathrm{B}$ and $\mathrm{C}(P<0.05)$, and groups $\mathrm{C}$ and $\mathrm{D}(P<0.05$, Figure 1$)$. None of the patients were converted to an open surgical procedure. Postoperative complications are shown in Table 3. Transient hypocalcemia was 


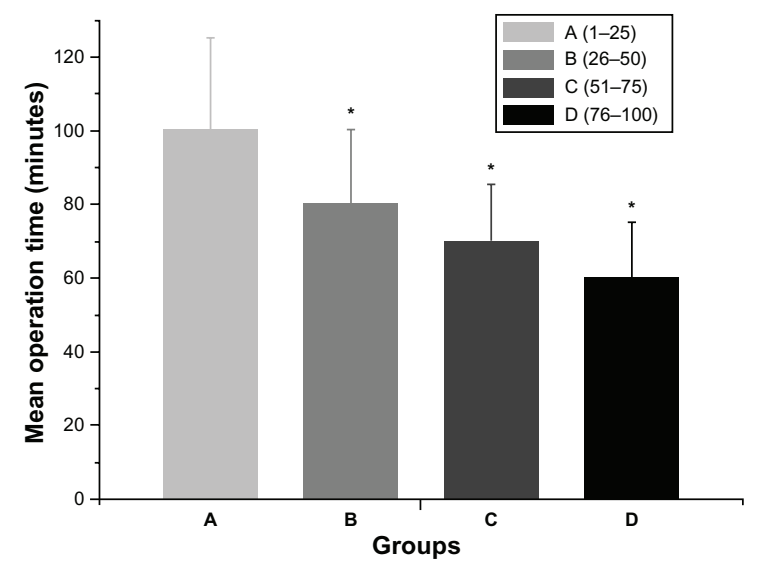

Figure I Mean operation time of endoscopic thyroidectomy (unilateral lobectomy).

found in one patient. No permanent hypocalcemia occurred. Transient recurrent laryngeal nerve palsy occurred in three patients. No permanent recurrent laryngeal nerve palsy occurred. Postoperative pain was reported by five patients at 24 hours following surgery.

Seventy-seven patients had nodular goiter on histopathological examination (Table 4). Fifteen patients had follicular adenoma, and seven had Hurthle cell adenoma. Only one patient had cystic lesions.

\section{Discussion}

A learning curve for an operation refers to the number of cases a surgical firm needs to perform before the operative time and complication rate become reproducibly minimized. ${ }^{24}$ However, a more signifying definition is needed, with renewal of estimation criteria for different surgical styles. The learning curve seems to be a more scientific estimation system for the perioperative period, which should include the appropriateness of the chosen surgical indications, rationality of the procedural steps, quality of manipulation, recovery of the patient, and postoperative quality of life. ${ }^{25,26}$ Based on all these considerations, the clinical directive effect of the learning curve should be complete.

Since the first case in January 2007, 355 patients have undergone endoscopic thyroidectomy at our study center during the past 5 years. All these procedures were performed by a single surgeon (FC). We collected the first 100 cases and divided them into four consecutive groups chronologically, each group comprising 25 cases.

Endoscopic thyroidectomy requires a great deal of experience in thyroid surgery, correct selection of patients, and proper performance and management of the endoscopic procedure. Perfect anatomical knowledge of the neck and solid surgical experience in total thyroidectomy are fundamental elements of the endoscopic surgical approach. All new procedures have a learning curve. Therefore, in our experience, the first problem was the operative time. We observed a shortening of the operative time after treatment of the first 25 cases.

As described in the surgical procedure, magnification of the endoscope allowed easy identification of the recurrent laryngeal nerve. Transient/permanent recurrent laryngeal nerve palsy is one of the common complications of endoscopic thyroidectomy. With the lateral view of the thyroid gland, we easily identified and preserved the recurrent laryngeal nerve while performing the endoscopic thyroidectomy. However, some major improvements and safer technologies, such as intraoperative neuromonitoring to prevent paralysis of the recurrent laryngeal nerve, have been proposed and would be considered for application in thyroid surgery in subsequent years. ${ }^{27}$

In conclusion, we consider that endoscopic thyroidectomy should be performed when the inclusion criteria are met. However, the surgeon must be expert in open thyroid surgery to be able to undertake this surgical approach.

Table 3 Postoperative complications

\begin{tabular}{|c|c|c|c|c|c|}
\hline \multirow[t]{2}{*}{ Postoperative complications } & \multicolumn{5}{|l|}{ n (\%) } \\
\hline & $\begin{array}{l}\text { Endoscopic thyroidectomy } \\
(n=100)\end{array}$ & $\begin{array}{l}\text { Group A } \\
(n=25)\end{array}$ & $\begin{array}{l}\text { Group B } \\
(n=25)\end{array}$ & $\begin{array}{l}\text { Group C } \\
(n=25)\end{array}$ & $\begin{array}{l}\text { Group D } \\
(n=25)\end{array}$ \\
\hline Transient RLN palsy & $3(3)$ & I (4) & I (4) & I (4) & 0 \\
\hline Permanent RLN palsy & 0 & 0 & 0 & 0 & 0 \\
\hline Transient hypocalcemia & $\mathrm{I}(\mathrm{I})$ & I (4) & 0 & 0 & 0 \\
\hline Permanent hypocalcemia & 0 & 0 & 0 & 0 & 0 \\
\hline Redo surgery for hemorrhage & 0 & 0 & 0 & 0 & 0 \\
\hline Postoperative pain & $5(5)$ & $2(8)$ & I (4) & I (4) & I (4) \\
\hline Hoarse voice & $2(2)$ & I (4) & I (4) & 0 & 0 \\
\hline Swallowing difficulty & 0 & 0 & 0 & 0 & 0 \\
\hline Hypesthesia or paresthesia & $\mathrm{I}(\mathrm{I})$ & I (4) & 0 & 0 & 0 \\
\hline
\end{tabular}

Abbreviation: RLN, recurrent laryngeal nerve. 
Table 4 Histopathological findings

\begin{tabular}{|c|c|c|c|c|c|}
\hline \multirow[t]{2}{*}{ Histopathology } & \multicolumn{5}{|l|}{ n (\%) } \\
\hline & $\begin{array}{l}\text { Endoscopic thyroidectomy } \\
(n=100)\end{array}$ & $\begin{array}{l}\text { Group A } \\
(n=25)\end{array}$ & $\begin{array}{l}\text { Group B } \\
(n=25)\end{array}$ & $\begin{array}{l}\text { Group C } \\
(n=25)\end{array}$ & $\begin{array}{l}\text { Group D } \\
(n=25)\end{array}$ \\
\hline Nodular goiter & 77 (77) & $19(76)$ & $17(68)$ & $22(88)$ & $19(76)$ \\
\hline \multicolumn{6}{|l|}{ Adenoma } \\
\hline Follicular adenoma & $15(15)$ & $3(12)$ & $5(20)$ & $2(8)$ & $5(20)$ \\
\hline Hurthle cell adenoma & $7(7)$ & $2(8)$ & $3(12)$ & I (4) & I (4) \\
\hline Cystic lesions & I (I) & I (4) & 0 & 0 & 0 \\
\hline
\end{tabular}

\section{Acknowledgments}

This work was supported by the Zhejiang Provincial Medical and Healthy Science and Technology Projects (2011KYB137), Science Research Fund of Taizhou (A102KY09), Science Research Fund of Shaoxing (2011D10013), and Science Research Fund of Zhuji (2011CC7874).

\section{Disclosure}

The authors report no conflicts of interest in this work.

\section{References}

1. Kelman AS, Rathan A, Leibowitz J, Burstein DE, Haber RS. Thyroid cytology and the risk of malignancy in thyroid nodules: importance of nuclear atypia in indeterminate specimens. Thyroid. 2001;11(3):271-277.

2. Tuttle RM, Lemar H, Burch HB. Clinical features associated with an increased risk of thyroid malignancy in patients with follicular neoplasia by fine-needle aspiration. Thyroid. 1998;8(5):377-383.

3. Goldstein RE, Netterville JL, Burkey B, Johnson JE. Implications of follicular neoplasms, atypia, and lesions suspicious for malignancy diagnosed by fine-needle aspiration of thyroid nodules. Ann Surg. 2002;235(5):656-662.

4. Schlinkert RT, van Heerden JA, Goellner JR, et al. Factors that predict malignant thyroid lesions when fine-needle aspiration is "suspicious for follicular neoplasm”. Mayo Clin Proc. 1997;72(10):913-916.

5. Marqusee E, Benson CB, Frates MC, et al. Usefulness of ultrasonography in the management of nodular thyroid disease. Ann Intern Med. 2000;133(9):696-700.

6. Segev DL, Clark DP, Zeiger MA, Umbricht C. Beyond the suspicious thyroid fine needle aspirate. A review. Acta Cytol. 2003;47(5):709-722.

7. Cooper DS, Doherty GM, Haugen BR, et al; American Thyroid Association Guidelines Taskforce. Management guidelines for patients with thyroid nodules and differentiated thyroid cancer. Thyroid. 2006; 16(2):109-142.

8. Sherman SI. Thyroid carcinoma. Lancet. 2003;361(9356):501-511.

9. Gharib H, Goellner JR, Johnson DA. Fine-needle aspiration cytology of the thyroid. A 12-year experience with 11,000 biopsies. Clin Lab Med. 1993;13(3):699-709.

10. Skinner MA, Moley JA, Dilley WG, Owzar K, Debenedetti MK, Wells SA Jr. Prophylactic thyroidectomy in multiple endocrine neoplasia type 2A. N Engl J Med. 2005;353(11):1105-1113.

11. Nel CJ, van Heerden JA, Goellner JR, et al. Anaplastic carcinoma of the thyroid: a clinicopathologic study of 82 cases. Mayo Clin Proc. 1985;60(1):51-58.
12. Gough IR, Wilkinson D. Total thyroidectomy for management of thyroid disease. World J Surg. 2000;24(8):962-965.

13. Cao FL, Xie BJ, Cui BB, Xu D. Endoscopic vs conventional thyroidectomy for the treatment of benign thyroid tumors: a retrospective study of a 4-year experience. Exp Ther Med. 2011;2(4):661-666.

14. Brunaud L, Germain A, Zarnegar R, Klein M, Ayav A, Bresler L. Robotic thyroid surgery using a gasless transaxillary approach: cosmetic improvement or improved quality of surgical dissection? J Visc Surg. 2010;147(6):e399-e402.

15. Lee J, Chung WY. Current status of robotic thyroidectomy and neck dissection using a gasless transaxillary approach. Curr Opin Oncol. 2012;24(1):7-15.

16. Hüscher CS, Chiodini S, Napolitano C, Recher A. Endoscopic right thyroid lobectomy. Surg Endosc. 1997;11(8):877.

17. Duncan TD, Rashid Q, Speights F, Ejeh I. Endoscopic transaxillary approach to the thyroid gland: our early experience. Surg Endosc. 2007;21(12):2166-2171.

18. Cho YU, Park IJ, Choi KH, et al. Gasless endoscopic thyroidectomy via an anterior chest wall approach using a flap-lifting system. Yonsei Med J. 2007;48(3):480-487.

19. Palazzo FF, Sebag F, Henry JF. Endocrine surgical technique: endoscopic thyroidectomy via the lateral approach. Surg Endosc. 2006;20(2):339-342.

20. Witzel K, von Rahden BH, Kaminski C, Stein HJ. Transoral access for endoscopic thyroid resection. Surg Endosc. 2008;22(8):1871-1875.

21. Lee KE, Kim HY, Park WS, et al. Postauricular and axillary approach endoscopic neck surgery: a new technique. World J Surg. 2009;33(4):767-772.

22. Ng WT. Endoscopic thyroidectomy in China. Surg Endosc. 2009; 23(7):1675-1677.

23. Zhang W, Jiang DZ, Liu S, et al. Current status of endoscopic thyroid surgery in China. Surg Laparosc Endosc Percutan Tech. 2011;21(2):67-71.

24. Leong S, Cahill RA, Mehigan BJ, Stephens RB. Considerations on the learning curve for laparoscopic colorectal surgery: a view from the bottom. Int J Colorectal Dis. 2007;22(9):1109-1115.

25. Ahlberg G, Kruuna O, Leijonmarck CE, et al. Is the learning curve for laparoscopic fundoplication determined by the teacher or the pupil? Am J Surg. 2005;189(2):184-189.

26. Gill J, Booth MI, Stratford J, Dehn TC. The extended learning curve for laparoscopic fundoplication: a cohort analysis of 400 consecutive cases. J Gastrointest Surg. 2007;11(4):487-492.

27. Witzel K, Benhidjeb T. Monitoring of the recurrent laryngeal nerve in totally endoscopic thyroid surgery. Eur Surg Res. 2009;43(2):72-76. 


\section{Publish your work in this journal}

OncoTargets and Therapy is an international, peer-reviewed, open access journal focusing on the pathological basis of all cancers, potential targets for therapy and treatment protocols employed to improve the management of cancer patients. The journal also focuses on the impact of management programs and new therapeutic agents and protocols on patient perspectives such as quality of life, adherence and satisfaction. The manuscript management system is completely online and includes a very quick and fair peer-review system, which is all easy to use. Visit http://www.dovepress.com/testimonials.php to read real quotes from published authors.

Submit your manuscript here: http://www.dovepress.com/oncotargets-and-therapy-journal 